\title{
MARXismo y ATEÍSMO. RECUPERANDO EL DEBATE
}

\author{
MarXism and Atheism. Recolering the Debate \\ Luis Felip López-Espinosa \\ DOI: $10.26754 /$ ojs_arif/a.rif.202013938
}

\begin{abstract}
RESUMEN
El marxismo se suele identificar con un rechazo sin matices de la religión. Dos publicaciones recientes afrontan esta simplificación: El dispositivo Karl Marx, de Juan Manuel Aragüés, y la recopilación de textos de Marx Sobre la religión, con estudio preliminar de Reyes Mate y José A. Zamora. En esta nota vamos a hacer una lectura cruzada de dichos trabajos. Pretendemos revitalizar el problema del ateísmo no sólo desde las contribuciones más recientes, sino también retornando a los textos de Marx. Contra las simplificaciones, el ateísmo teórico de Marx debe entenderse a partir de su concepción materialista de la historia, compatible con el humanismo práctico de quienes compartan el propósito de una política emancipatoria.
\end{abstract}

PALABRAS ClAVE: Marxismo, Marx, religión, ateísmo, materialismo, historia

\begin{abstract}
Marxism is often identified with the outright rejection of religion. Two recent publications look at this simplification: El dispositivo Karl Marx, by Juan Manuel Aragüés, and the compilation of Marx's texts Sobre la religión, with a preliminary study by Reyes Mate and José A. Zamora. In this article we are going to read these two works in tandem. We intend to shed new light on the problem of atheism, not just looking at the most recent contributions, but also by returning to Marx's texts. The theoretical atheism of Marx should not be oversimplified and indeed one must see it as a consequence of his materialist conception of history, which is compatible with the practical humanism of those who share his goal of a politics of emancipation.
\end{abstract}

KEYWORDS: Marxism, Marx, Religion, Atheism, Materialism, History 


\section{1. ¿ES EL MARXISMO UN ATEÍSMO?}

¿Existe en Marx una verdadera crítica a la religión? ¿Es el marxismo, sin más, un ateísmo? Dos preguntas que deben responderse por separado, y es posible que en un sentido contradictorio, pues de la disolución y reconstrucción del sentido del término "ateísmo" se siguen consecuencias prácticas de enorme importancia para la teoría marxista y para la práctica política emancipadora.

En su estudio introductorio a los escritos de Marx Sobre la religión. De la alienación religiosa al fetichismo de la mercancía, Reyes Mate y José A. Zamora recuerdan que la primera edición de esta recopilación de textos tenía un sentido militante muy claro en 1973: vencer el mito de la incompatibilidad entre marxismo y religión, que se tenía como un hecho dentro de la tradición del marxismo ortodoxo y del movimiento comunista.

Esta identificación persiste en obras muy recientes y meditadas, y el propio Carlos Fernández Liria la asume en su libro En defensa del populismo, al calor de los desencuentros políticos recientes entre la izquierda. Fernández Liria retoma el argumento de la Crítica de la razón política de Régis Debray para denunciar que las sociedades del "socialismo real" operaban como "una caja negra en la que entraba un ateísmo radical y salía una religión mundial" (Fernández Liria 2016: 44) en forma de nuevos rituales y ceremonias. El marxismo aún a día de hoy habría "entregado la religión al enemigo", para terminar creando una religión laica poco ilusionante y en absoluto movilizadora, y habría desaprovechado el potencial emancipador del cristianismo y del catolicismo en particular (Id. 138-151).

Pero la realidad es que, históricamente, en España la relación entre el movimiento comunista y el catolicismo era mucho más compleja y desmitificadora que el supuesto ateísmo del marxismo "ortodoxo". Si en 1973 Reyes Mate y José A. Zamora afirman que "se podía ser cristiano y marxista" (Mate y Zamora 2018: 13), es porque, como ellos mismos recuerdan, desde los años 60 nos encontrábamos en un contexto de acercamiento entre marxismo y catolicismo tras el Concilio Vaticano II y tras la aparición de la teología de la liberación. En Chile, los democristianos se habían integrado en la Unidad Popular de Allende (Allende 1973: 15), y en España el movimiento de católicos de base va a converger, no sin dificultades, con el principal actor político de la lucha antifranquista, el PCE (Morán 2017: 843), dando asimismo un impulso fundamental a las Comisiones Obreras.

Si esto es así, puede parecer paradójico que casi a renglón seguido se nos descubra como tesis central de los editores que la crítica de la religión "es capital no solo para entender la religión o nuestro tiempo, sino también para la vuelta de Marx" (Mate y Zamora 2018: 16). ¿Significa acaso esto que el marxismo sólo puede 
ser reactivado como un ateísmo? ¿O que, a un nivel práctico, toda unidad de acción entre marxismo y religión, o entre socialismo y cristianismo, resultaría imposible?

\section{2. ¿QUÉ ES EL ATEÍSMO DE MARX?}

El libro de Juan Manuel Aragüés, El dispositivo Karl Marx. Potencia politica y lógica materialista, es una reivindicación expresa del ateísmo de Marx. En una obra compleja y en ocasiones hasta contradictoria, maltratada históricamente desde la simplificación y la caricatura, Aragüés afirma el ateísmo de Marx como "dispositivo ontológico que sobredetermina el conjunto de su obra y que, además, permite una lectura materialista de la misma" (Aragüés 2018: 12). En este aspecto, y siguiendo la tradición althusseriana, nos encontraríamos con un Marx más próximo a la filosofía de la inmanencia de Spinoza y al nihilismo de Nietzsche que al idealismo hegeliano (vínculo que, sin negarlo en absoluto, habría sido maximizado hasta ocultar los aspectos más relevantes del materialismo de Marx).

Ahora bien, ¿qué entiende Aragüés por "ateísmo”? ¿Nos está diciendo que el centro filosófico de Marx se encuentra en la crítica de la religión? Es cierto que a lo largo de la obra de Marx podemos encontrar numerosísimas reflexiones en este sentido. Siempre estarán enmarcadas en un materialismo que irá evolucionando conforme se desarrolle su propia obra, desde sus primeras críticas a Hegel hasta sus análisis del fetichismo de la mercancía. Así lo muestra la excelente recopilación de textos de Mate y Zamora, que los autores estructuran, en su estudio introductorio, en torno a cuatro etapas.

La primera etapa estaría marcada por la centralidad de la crítica filosófica a la religión. La obra principal de este período es la tesis doctoral de Marx sobre Demócrito y Epicuro (Mate y Zamora 2018: 26). La crítica de Marx se enmarca en la disputa entre izquierda y derecha hegelianas, y bebe de la tradición ilustrada y del ateísmo de Feuerbach, con quien sin embargo también polemiza. Marx afirma, con los jóvenes hegelianos, que Dios es una creación humana; pero hay que ir más al fondo de la cuestión y preguntarse por los motivos de dicha creación: "la idea de Dios aparece en la historia porque la vida real está desgarrada por la miseria" (Id. 25). Pero esta crítica a la religión es filosófica y no es aún política, pues el empeño de Marx sería enfrentar, desde la filosofía, una tradición hegeliana que se mueve entre la contemplación filosófica de la autoconciencia y la crítica filosófica a dicha autocontemplación (Id. 24).

La segunda etapa, que comienza en el periodo de la Rheinische Zeitung, es la de la crítica política de la religión y de la filosofía. Ahora, Marx va a ahondar en 
esas causas de la religión desde el conocimiento de la realidad de su época. Aquí el problema es la relación entre Estado y religión, una relación que toma su forma más perversa en el Estado confesional prusiano. Los debates filosóficos son inseparables de los debates políticos, por cuanto que la filosofía y la crítica de la religión son un terreno más para la lucha política (Mate y Zamora 2018: 30). Cuando Marx se exilie a París y comience a trabajar en los Anales franco-alemanes, esta relación entre filosofía y política no hará más que ahondarse, tanto en el plano epistemológico ("el sujeto que piensa tiene que ser el sujeto que sufre", es decir, el proletariado [Id.33]) como en la crítica a la filosofía del Estado de Hegel.

Para Marx, la crítica a la religión es el modelo a partir del cual pensar la crítica de la política, como especifican los primeros párrafos de la Crítica de la filosofía del derecho de Hegel (Mate y Zamora 2018: 37). La crítica a la religión, "condición primera de toda crítica" (Marx 1970a: 101), nos permite pensar el Estado por cuanto que, desenmascarada la religión como "mundo invertido", entendemos la prioridad de averiguar la verdad sobre el mundo verdadero (las relaciones sociales que explican por tanto el hecho religioso). Aquí, Marx encuentra un papel doble de la religión:

- La religión es una forma de justificación de lo que existe, una "cámara oscura” que refleja las relaciones sociales de forma invertida, como desarrollará más adelante en La ideología alemana (Marx y Engels 2014: 21).

- Pero la religión no es mera ideología, porque es también una forma de protesta contra las condiciones miserables de existencia del ser humano (Mate y Zamora 2018: 38-39; Marx 2014: 500).

Por cuanto que existe este carácter doble, y la religión se entiende también como una forma de dar cabida a las esperanzas frustradas de felicidad para las clases dominadas, entendemos que Marx no se adscriba sin más a la crítica destructiva de la religión propia de la Ilustración o de la izquierda hegeliana. En su respuesta a Bruno Bauer acerca de La cuestión judía, Marx va a plantear precisamente los límites del laicismo. Según Bauer, el Estado confesional deshumanizaba a quien no fuese cristiano. Pero Marx responde que el Estado laico no basta para la emancipación del ser humano, por cuanto que los derechos del ser humano abstracto son, bajo el liberalismo, meros derechos formales que constituyen, en realidad, las condiciones de posibilidad para la desigualdad real (Mate y Zamora 2018: 43). De este modo, Marx va a concluir que "la puesta en práctica del idealismo del Estado fue, al mismo tiempo la puesta en práctica del materialismo de la sociedad burguesa" (Marx 1970b: 247). Es la libertad formal burguesa la que hace 
posible la libertad del obrero respecto de sus medios de subsistencia, y el "libre" contrato con el explotador que posee los medios de producción. El liberalismo, al reconocer a los seres humanos como libres e iguales, convierte la desigualdad real en un asunto privado, fruto de la elección de los individuos en el ejercicio de su idéntica libertad. Así pues, se preguntan Mate y Zamora, ¿es realmente laico el Estado liberal? A pesar de que Marx había afirmado contundentemente que el capitalismo destruye todo lazo de pertenencia para reemplazarlo por el mero "pago al contado" (Marx y Engels 1975: 24), los autores extraen de la crítica a Bauer que según Marx, el Estado libre de religión está amparando una nueva forma de religiosidad, "porque esa sociedad estaría guiada por un valor absoluto al que todos tienen que rendir culto: el dinero" (Mate y Zamora 2018: 44). Aunque Marx no se expresa en esos términos, ciertamente de su análisis se extrae que el supuesto materialismo liberal constituye realmente un idealismo que esencializa el egoísmo del bomo oeconomicus burgués. Ahora bien, como señalan los autores, en esta etapa aún nos encontramos en Marx con el presupuesto de que la emancipación política se alcanza por medio de la crítica. Aunque existe un distanciamiento de la filosofía y una mirada a la realidad, seguimos en el marco de la crítica reflexiva y de un concepto abstracto de "realidad" (Id. 46).

La tercera etapa de la reflexión de Marx estaría presidida por los Manuscritos de 1844, las Tesis sobre Feuerbach y La ideología alemana. Aquí, Marx desciende de la crítica del Estado a la crítica de la sociedad, y toma como punto de partida al ser humano como ser que trabaja (Mate y Zamora 2018: 47). El materialismo histórico empieza a construirse pues a partir de la concepción materialista del ser humano como ser que trabaja. Y para ello, en un giro materialista inspirado en Feuerbach, hay que dejar de tomar en consideración otros fenómenos sociales que queden fuera de este enfoque: "la moral, la religión, la metafísica y cualquier otra ideología (...) pierden, así, la apariencia de su propia sustantividad” (Marx y Engels 2014: 21). Según los editores, ello supondría sin embargo "dejar fuera de consideración muchos de los sufrimientos humanos que habían centrado hasta ahora toda su atención" (Mate y Zamora 2018: 50).

La última etapa, tras esta definición del materialismo histórico como ciencia de la historia de los modos de producción, será la del Marx "maduro" y de la crítica de la economía política. El concepto central de esta etapa va a ser su análisis del fetichismo de la mercancía. Habíamos afirmado que el Estado liberal abre paso a una nueva forma de religiosidad, si bien no será una forma expresa sino una forma implícita, tal como interpretará Walter Benjamin al extraer las consecuencias últimas de la tesis weberiana sobre el espíritu del capitalismo (Löwy 2009). El 
capitalismo no necesita ya de la religión, y en esa medida vivimos en una sociedad secularizada donde la crítica de la religión resulta superflua. Y sin embargo, en el capitalismo la forma mercancía no es sino el ejemplo del fetichismo propio de esa nueva religiosidad, donde las relaciones sociales aparecen reificadas y con propiedades subjetivas, como relaciones entre cosas (Mate y Zamora 2018: 56-57). El fetichismo de la mercancía, el ocultamiento de las relaciones sociales que subyacen a la economía capitalista, no es susceptible ya de una crítica al estilo del ateísmo ilustrado, puesto que es fundamentalmente un resultado de la praxis inconsciente de los individuos ("no lo saben, pero lo bacen" [Marx 1975: 90]). Al intercambiar las mercancías por su valor de cambio, los individuos adoptan como natural una realidad (y una temporalidad: la de la acumulación capitalista) sobrenatural, fruto de relaciones sociales históricas y transitorias. Es por ello que, para el Marx maduro, la crítica del fetichismo de la mercancía no puede desarrollarse en el ámbito de la conciencia, sino en el ámbito de una praxis anticapitalista.

A partir de esta evolución en la obra de Marx, podemos contextualizar el significado de la crítica de la religión en su obra. Que la crítica de la religión constituya el modelo de toda la crítica posterior, significa que ésta resulta fundamental para entender la obra de Marx, pero no autoriza a reducir toda la obra de Marx a crítica de la religión. La obra del Marx maduro, como indicaba Althusser, es una crítica de la economía política, un análisis del modo de producción capitalista, y no una obra filosófica, una crítica de la cultura ni una antropología. Como bien destacan Reyes Mate y José A. Zamora, el materialismo histórico se constituye deslindando muy nítidamente su objeto y su ámbito de reflexión, y, para bien o para mal, entiende que la filosofía y la crítica a la religión estarían más allá de los límites de la teoría materialista de la historia y de la crítica de la economía política.

Por eso, y retomando los interrogantes con los que partíamos, la obra de Marx no constituye una crítica de la religión al modo de los hegelianos de izquierda o la filosofía de la Ilustración. Buena parte de la obra de Marx, de hecho, se dedica a la crítica de aquella izquierda hegeliana que dormitaba en el marco intelectual de sus predecesores y se limitaba a "dar la vuelta" al idealismo hegeliano. Pero la crítica apolítica a la religión, que se ejerce desde los mismos presupuestos del idealismo, sin bajar a las realidades, es una crítica igualmente idealista: "solo, por tanto, a través de la praxis política es posible llevar a su culminación los efectos de la crítica, teórica, de la religión" (Aragüés 2018: 23). Esa culminación no es ya una crítica de la religión, sino una crítica del capitalismo que ha reemplazado a la propia religión por medio de una forma de dominación ideológica fundada en la praxis. 


\section{3. ¿Proceso sin Sujeto ni Fin(es) O Mesianismo Benjaminiano?}

Como hemos visto, la crítica a la religión en Marx se desarrolla a lo largo de varias décadas de trabajo intelectual. Marx parte del hegelianismo de izquierda, para finalmente ajustar cuentas con toda su "conciencia filosófica anterior" (Marx y Engels 1989: 8) y dar forma a un materialismo histórico y a una crítica de la economía política que suponen el abandono de las coordenadas feuerbachianas.

En efecto, el primer gran crítico de la religión habría sido Feuerbach (antes de Nietzsche). Como recuerda Aragüés citando a Deleuze, "el último pensador de la muerte de Dios es Feuerbach" (Aragüés 2018: 15). Pero es precisamente contra Feuerbach, y contra la izquierda hegeliana en general, que Marx dirige algunas de sus primeras críticas filosóficas. Feuerbach es culpable de no haber llevado su ateísmo a las últimas consecuencias: al criticar la alienación religiosa como alienación de la esencia humana, está asumiendo la existencia de una esencia humana genérica, universal, ahistórica (Mate y Zamora 2018: 49). Esta crítica lleva a sus últimas consecuencias el ateísmo del propio Feuerbach. Y nos descubre que el viejo ateísmo de tradición ilustrada, el ateísmo burgués, se encuentra preso de las mismas claves ontológicas que la religión.

Por tanto, para Aragüés, cuando hablamos en Marx de ateísmo, no se trata tanto de un intento de "desmontar" la religión, sino de que Marx piense en las coordenadas que inaugura la "muerte de Dios", extrayendo las conclusiones lógicas de la misma. No se trata ya de erigir un discurso iconoclasta, sino del despliegue de un pensamiento "ateo" acerca de la historia, del sujeto y de la praxis política. Esta ontología de Marx consistirá en una ontología del devenir y de la multiplicidad: "El Ser, estático y compacto, trasunto de la divinidad, deja paso al devenir temporal y a la multiplicidad espacial, social y cultural" (Aragüés 2018: 26).

La obra de Marx, como dijimos, es altamente contradictoria. El propio concepto central del materialismo histórico, el concepto de historia, es susceptible de lecturas contrapuestas, entre el voluntarismo y el economicismo. Para Aragüés, debemos interpretar la noción marxiana de historia a partir de las claves ontológicas que acabamos de analizar. Siendo así, aunque podemos reconocer en la teoría de la historia de Marx una recurrencia de elementos epocales como son el etapismo, el progresismo y el teleologismo (Aragüés 2018: 38; Mate y Zamora 2018: 66), al mismo tiempo encontramos una reivindicación del papel del sujeto y su praxis (Aragüés 2018: 45) y un cuestionamiento de todo materialismo contemplativo.

Frente al Marx anquilosado y determinista, Aragüés nos conmina a recuperar a un Marx centrado en la subjetividad política (el proletariado) y en la construcción de una colectividad antagonista. También nos recuerda, a partir de las 
reflexiones sobre la comuna rural rusa, la multiplicidad de caminos que puede seguir el desarrollo histórico. Por ello, como señalan Fernández Liria y Alegre, Marx no pretendía descubrir las leyes de la historia, sino más modestamente, señalar que hay leyes en la historia (Cit. en Aragüés 2018: 58). Todo ello es contrario a cualquier idea de finalidad o teleología.

Lo que Aragüés llama el "ateísmo" de Marx tiene que ver por tanto con su concepción de la historia como, en palabras de Althusser, un "proceso sin Sujeto ni Fin(es)" (Althusser 1973). La "inversión" del idealismo hegeliano por parte de Marx implica entender la inmanencia de los sujetos y de los fines al propio proceso histórico, y de este modo toda la historia del pensamiento se entiende, para Aragüés, como

contraposición entre un pensamiento de la transcendencia, que el poder siempre ha utilizado como instrumento de afianzamiento de su dominio, y un pensamiento inmanente, libre de toda servidumbre y abierto al vértigo de la producción materialista. (Aragüés 2018: 131)

Por eso hay que recuperar la crítica marxiana al humanismo esencialista de Feuerbach, y entender que lo que sería en Marx una "antropología de la diferencia" se opone a toda forma de esencialismo y de humanismo (Aragüés 2018: 62). Se trata de una antropología que se opone a la noción cartesiana de sujeto, comprendido ahora como "constructo social, como efecto de las múltiples mediaciones a las que está sometido" (Id. 28). El sujeto antagonista se entiende por tanto no como Sujeto de la historia ni como causa de la misma, sino como efecto de procesos de subjetivación, fruto de una realidad múltiple y en devenir (Id. 132).

Ahora bien, nos encontramos aquí con una disyuntiva. ¿Es posible pensar la transformación social desde la inmanencia? ¿O se precisa de un mínimo sentido de trascendencia para poder fundamentar la crítica a lo que existe? Esta segunda posición será la de Reyes Mate y José A. Zamora, para quienes, al contrario que Aragüés, el potencial de la crítica a la religión sigue siendo relevante. Si dijimos que, en una sociedad fetichizada, la propia praxis opera como religión, si afirmamos que vivimos en una secularización fallida, entonces no cabe dar por sentada la "muerte de Dios" y negar sin más toda operatividad tanto a la crítica de la religión como a las potencialidades de ciertas tradiciones religiosas (Mate y Zamora 2018: 66).

Siguiendo a Benjamin, Mate y Zamora identifican tres elementos para toda política alternativa (Mate y Zamora 2018: 75):

- El éxodo, como desvinculación con el Estado (el Estado-nación ligado al territorio) y al mismo tiempo como recuperación de la promesa y de la esperanza. 
- La bistoria como idea que permite la superación de la temporalidad capitalista (que es siempre la temporalidad de la acumulación de capital).

- La conversión en tanto fórmula que permite superar el abismo entre capitalismo y socialismo.

El mesianismo benjaminiano hace posible precisamente la ruptura de la dinámica capitalista, algo que sería imposible si nos situamos desde la inmanencia. El reino no se entiende por tanto como meta inmanente de la historia, sino como el final de la historia (Mate y Zamora 2018: 77), y ello es importante porque nos permite romper con el concepto lineal y teo-teleológico de la historia tal como se entiende en el capitalismo. El tiempo capitalista no permite la redención, porque es un tiempo entendido de forma acumulativa y circular, que nos atrapa en el movimiento de valorización y de reproducción ampliada (Id. 80). En cambio, debemos recuperar otra idea del tiempo que abre el presente a la memoria de la felicidad perdida y a la memoria de los derrotados.

Pero, ¿significa esto que Benjamin "supera” a Marx? ¿Es inevitable entender el concepto de historia marxiano como una repetición del concepto burgués de historia? ¿Sustituye Marx la historia burguesa por una "lógica" del capital (Mate y Zamora 2018: 83) que no es sino la repetición de sus mismos clichés (linealidad, necesidad, teleología)? Como hemos visto siguiendo a Aragüés, aunque exista una tendencia en el llamado marxismo "ortodoxo" a esta lectura, es posible otra interpretación de Marx crítica con los clichés teo-teleológicos y solidaria por tanto de la crítica marxiana de la religión. Una lectura que está en Benjamin, pero también en el propio Marx. Cuando Gramsci afirmaba que la revolución rusa había sido una revolución “contra El capital' (Gramsci 1977: 34), realmente de lo que se trataba era de combatir cierta lectura del mismo (Aragüés 2018: 120), una lectura economicista, determinista y teleológica, que como hemos visto resulta contradictoria con la imagen mucho más abierta y plural que sostiene Marx acerca del proceso histórico.

Para enfrentarnos a esta visión, resulta de utilidad recuperar los textos para recomponer una interpretación no vulgar de la concepción materialista de la historia en Marx. Como afirma César Ruiz Sanjuán (2019: 134), Marx nunca emplea el término de "materialismo histórico", que Engels tomará de Mehring, y que, adoptado por el marxismo ortodoxo, reduce el proceso histórico a una dialéctica (protohegeliana) entre fuerzas productivas y relaciones de producción (Id. 146). Pero también debemos tomar precauciones respecto de lecturas como la de Reyes Mate y José A. Zamora, y aplicarles la misma crítica que a aquellas interpretaciones propias del marxismo occidental que corren el peligro de proyectar las tesis feuerbachianas y hegelianas del primer Marx sobre el resto de su obra (Id. 105). Es 
en este sentido que debemos entender la ruptura de las obras de 1845 (La ideología alemana y las Tesis sobre Feuerbach) con, como ya advirtiese Zelený, "los restos de elementos de la concepción teológico-escatológica del comunismo, de la historia, del ser humano y de la realidad" (Cit. en Id. 108). Ruiz Sanjuán, en su excelente lectura sobre el concepto de historia en Marx, sostiene que frente a esta insistencia en la coherencia entre el primer Marx y el Marx "maduro", debemos reafirmar la incoherencia interna de la obra de Marx. En lugar de un despliegue de las categorías de los Manuscritos, debemos reafirmar la ruptura de Marx con sus propios presupuestos filosóficos e ideológicos.

Si en Marx existe por tanto una ruptura, contradictoria en muchos casos, con categorías que no son sino un resto de la noción burguesa de la historia, entonces cabría también pensar el comunismo sin necesidad de la noción mesiánica de la trascendencia. Abandonamos por tanto el comunismo como realización de la esencia humana genérica (Ruiz Sanjuán 2019: 128) y retomamos la idea de Marx del comunismo como el "movimiento real que anula y supera el estado de cosas actual” (Marx y Engels 2014: 29).

¿Dónde queda entonces ese comunismo, que no es el despliegue de la esencia en el marco de un proceso histórico telelógico y determinista? Mirando a Spinoza, como hace Aragüés, debemos pensar la subjetividad subalterna como una subjetividad inmanente que se autoproduce en el ámbito de la historia. En sus prácticas alternativas podemos poner en práctica una "imaginación constituyente" (Aragüés 2018: 121) del común, una anticipación del comunismo en las grietas y contradicciones del presente, que se opondría a esa temporalidad reiterativa que Mark Fisher llama "realismo capitalista" (Fisher 2018: 22). Siguiendo a Spinoza, ese sujeto es la multitud que aumenta, en el colectivo, su potencia de obrar (Aragüés 2018: 135).

\section{CONCLUSiOnes}

En este trabajo hemos analizado dos posiciones acerca del ateísmo en Marx. De una parte, la crítica de la religión abre la posibilidad a un mesianismo para el cual el socialismo es la trascendencia que supera la incompleta secularización del capitalismo. La religión, sometida a crítica en buena parte de la obra de Marx, es una parte más de la memoria de los oprimidos y el trabajo del materialista histórico es integrarla para pensar una ruptura con la temporalidad capitalista. Se trata de un delicado equilibrio entre mesianismo y ateísmo: el verdadero ateísmo es la crítica de aquella ideología práctica vigente en la imperfecta secularización capitalista, 
y la religión no es ya sino el impulso de transformar esta sociedad para cumplir una promesa de felicidad que se nos adeuda históricamente.

Por otra parte, el ateísmo de Marx no tiene que ver con la crítica de la religión al modo de la filosofía ilustrada, sino con una ontología de la historia que la separa de toda teleología (por consiguiente, también de las lecturas economicistas y deterministas de Marx). Desde este punto de vista, el comunismo es la construcción del sujeto colectivo que, inmanente a las contradicciones del capitalismo, imagina y proyecta otra sociedad. Aquí de nuevo, religión y ateísmo se encuentran en un equilibrio precario: el ateísmo es un pensamiento de la historia y una forma de habitar el mundo, abierto a una comunidad que construye el comunismo del futuro sin certezas y sin profecías. Una construcción que, a diferencia del ateísmo ilustrado, no se cierra a ninguna subjetividad (y caben aquí las subjetividades religiosas) que se implique en esa praxis revolucionaria.

Estas dos interpretaciones, la trascendente y la inmanente, nos permiten romper con una lectura ortodoxa del marxismo vulgar. Ahora bien, para cualquiera familiarizado con las corrientes del marxismo académico posteriores a los años cuarenta que Perry Anderson denominaba "marxismo occidental" (Anderson 1987), esta calificación de "ortodoxia" resulta problemática. ¿Acaso las lecturas de Marx más recientes, muchas de ellas basadas en la reactivación de tesis hegelianas o feuerbachianas, no se han constituído en una nueva ortodoxia? Para reconstruir un socialismo crítico, que cuestione los lugares comunes acerca de la obra de Marx, resulta indispensable retomar la trayectoria de una obra compleja y heterogénea, que discute y polemiza con sus propios supuestos. En este sentido, la filosofía implícita en Marx no se debe entender como principio, sino como conclusión y desarrollo de su análisis del desarrollo real del capitalismo histórico. En esta vuelta a Marx, que cuestione las viejas y las nuevas ortodoxias, la crítica de la religión retoma su lugar problemático, superada por la crítica de las contradicciones reales del modo de producción capitalista, e insuperada como modelo para toda crítica de la ideología y del fetichismo de la mercancía. En cualquiera de los casos, el ateísmo histórico de Marx se convierte en el mejor de los aliados para toda subjetividad antagonista, sin excluir al humanismo práctico de la filosofía ni de la religión.

Luis Felip López-Espinosa Universidad de Málaga felip885@gmail.com 


\section{BIBLIOGRAFÍA}

Allende, S. (1973): La vía chilena hacia el socialismo, Madrid: Fundamentos.

Althusser, L. (1973): "Observación sobre una categoría: 'proceso sin Sujeto ni Fin(es)"”, en Para una crítica de la práctica teórica. Respuesta a John Lewis, Madrid: Siglo XXI, pp. 74-81.

Anderson, P. (1987): Consideraciones sobre el marxismo occidental, Madrid: Siglo XXI.

ArAgÜÉs. J. M. (2018): El dispositivo Karl Marx. Potencia política y lógica materialista, Zaragoza: Prensas de la Universidad de Zaragoza.

FERnÁNDEZ LiRIA, C. (2016): En defensa del populismo, Madrid: Catarata.

FisHer, M. (2018): Realismo capitalista, Buenos Aires: Caja Negra.

Gramsci, A. (1977): Antología, Madrid: Siglo XXI.

LÖWY, M. (2009): “Capitalism as Religion: Walter Benjamin and Max Weber”, Historical Materialism, n. ${ }^{\circ} 17$, pp. 60-73.

Marx, K. (1970a): "Contribución a la crítica de la filosofía del derecho de Hegel", en

Marx, K. y Ruge, A., Los anales franco-alemanes, Madrid: Ediciones Martínez Roca, pp. 101-116.

MARx, K. (1970b): "La cuestión judía”, En Marx, K. y Ruge, A., Los anales franco-alemanes, Madrid: Ediciones Martínez Roca, pp. 223-249.

Marx, K. (1975): El capital, Madrid: Siglo XXI.

Marx, K. (1989): Contribución a la crítica de la economía politica, Moscú: Progreso.

MARx, K. (2014): “Tesis sobre Feuerbach”, en Marx, K. y Engels, F., La ideología alemana, Madrid: Akal, pp. 499-502.

Marx, K. y Engels, F. (1975): "Manifiesto del Partido Comunista”, en Marx, K. y Engels, F., Obras escogidas, vol. 1, Madrid: Akal, pp. 11-55.

MARx, K. y Engels, F. (2014): La ideologia alemana, Madrid: Akal.

Mate, R. y Zamora, J. A. (2018): "Estudio introductorio. Sentido y actualidad de la crítica marxiana", en Marx, K. Sobre la religión. De la alienación religiosa al fetichismo de la mercancia, Madrid: Trotta, pp. 11-89.

Morán, G. (2017): Miseria, grandeza y agonía del Partido Comunista de España. 1939-1985, Madrid: Akal.

Ruiz San Juan, C. (2018): Historia y sistema en Marx. Hacia una teoría crítica del capitalismo, Madrid: Siglo XXI. 